\title{
Trypanosoma cruzi: blood parasitism kinetics and their correlation with heart parasitism intensity during long-term infection of Beagle dogs
}

\author{
Vanja M Veloso/ ${ }^{+}$, Paulo MM Guedes, Isabel M Andrade, Ivo S Caldas, Helen R Martins, \\ Cláudia M Carneiro', George LL Machado-Coelho², Marta de Lana', \\ Lúcia MC Galvão ${ }^{3}$, Maria T Bahia, Egler Chiari ${ }^{3}$
}

Departamento de Ciências Biológicas, Instituto de Ciências Exatas e Biológicas ${ }^{1}$ Departamento de Análises Clínicas ${ }^{2}$ Departamento de Ciências Médicas, Escola de Farmácia, Campus Universitário, Universidade Federal de Ouro Preto, 35400-000 Ouro Preto, MG, Brasil ${ }^{3}$ Departamento de Parasitologia, Instituto de Ciências Biológicas, Universidade Federal de Minas Gerais, Belo Horizonte, MG, Brasil

The goals of the present study were to evaluate the kinetics of blood parasitism by examination of fresh blood, blood culture $(B C)$ and PCR assays and their correlation with heart parasitism during two years of infection in Beagle dogs inoculated with the Be-78, Y and ABC Trypanosoma cruzi strains. Our results showed that the parasite or its kDNA is easily detected during the acute phase in all infected animals. On the other hand, a reduced number of positive tests were verified during the chronic phase of the infection. The frequency of positive tests was correlated with T. cruzi strain. The percentage of positive BC and blood PCR performed in samples from animals inoculated with Be-78 and ABC strains were similar and significantly larger in relation to animals infected with the $Y$ strain. Comparison of the positivity of PCR tests performed using blood and heart tissue samples obtained two years after infection showed two different patterns associated with the inoculated T. cruzi strain: (1) high PCR positivity for both blood and tissue was observed in animals infected with Be-78 or ABC strains; (2) lower and higher PCR positivity for the blood and tissue, respectively, was detected in animals infected with $Y$ strains. These data suggest that the sensitivity of BC and blood PCR was T. cruzi strain dependent and, in contrast, the heart tissue PCR revealed higher sensitivity regardless of the parasite stock.

Key words: Trypanosoma cruzi - Beagle dogs - parasitemia - blood culture - blood and tissue PCR

American trypanosomiasis is a protozoan infection caused by the flagellate Trypanosoma (Schizotrypanum) cruzi, and it is widespread throughout the American Continent. Approximately 13 million people living Central and South America are currently estimated to be infected and 14,000 annual deaths are associated with the infection (WHO 2005).

Different approaches have been used to diagnose Chagas disease. Serologic tests are regularly used to detect antibodies against $T$. cruzi. These tests have high sensitivity, but they lack specificity due to antigenic cross-reactivity with parasites such as Leishmania and Trypanosoma rangeli (Marcon et al. 2002). In addition, positive results from blood culture (BC) and PCR have been found in patients previously demonstrating consistently negative serological tests (Ávila et al. 1993, Gomes et al. 1999, Castro et al. 2002), reinforcing the importance and need for simultaneous use of parasitological and molecular tests in Chagas disease diagnosis.

Financial support: FAPEMIG, UFMG, UFOP, CNPq

+ Corresponding author: vanjamv@iceb.ufop.br

Received 4 December 2007

Accepted 8 September 2008
The literature strongly suggests that the variable efficacies of parasitological methods, such as $\mathrm{BC}$ and xenodiagnosis, in Chagas disease diagnosis (Portela-Lindoso \& Shikanai-Yasuda 2003) are highly specific, but with low sensitivity (Chiari 1999).

Thus, molecular assays such as PCR have been proposed as good alternative tools for detection of T. cruzi kDNA in human (Russomando et al. 1992, Wincker et al. 1994b, Gomes et al. 1999) and animal blood (Araújo et al. 2002, Guedes et al. 2004). According to Castro et al. (2002), PCR is more sensitive than BC in detecting circulating parasites in blood samples collected from chagasic patients during different time periods. Previous studies have shown PCR sensitivities of $45 \%$ to $100 \%$ for blood from chronic chagasic patients when compared to serological, xenodiagnosis or BC tests (Ávila et al. 1993, Wincker et al. 1994a, Gomes et al. 1998, Chiaramonte et al. 1999). These differences could be explained by variable levels of parasitemia in infected individuals living in different endemic areas.

These observations raise the question of whether the parasitemia detected in the peripheral blood could be related to the tissue parasitism (TP) level and, consequently, to the pathogenesis of the chronic phase of the disease.

However, the kinetics of blood parasitism during long-term chronic infection and the correlation between parasitemia levels in the peripheral blood and TP are difficult to evaluate in humans. Considering that previous studies from our group using the canine model for Chagas disease have shown that these animals develop clini- 
cal manifestations identical to those observed in human patients (Lana et al. 1988, 1992, Bahia et al. 2002), this model would be more suitable for long-term evaluations. Therefore, this investigation was undertaken to evaluate the blood parasitism level during long-term infection of Beagle dogs inoculated with three different strains of $T$. cruzi and its correlation with heart TP.

\section{MATERIALS AND METHODS}

T. cruzi strains - T. cruzi Berenice-78 (Be-78) strain (T. cruzi II) was isolated by xenodiagnosis in 1978 (Lana \& Chiari 1986) from the first human case of Chagas disease; the Y strain (T. cruzi II) was isolated from an acute human case (Silva \& Nussenzweig 1953); and the ABC strain (T. cruzi) was isolated from a chronic human case (Brener 1965).

Experimental animals - 24-month-old Beagle dogs representing both sexes from the kennel of the Universidade Federal de Ouro Preto (UFOP), MG, Brazil, were used in this study. Animals were fed with commercial chow and water ad libitum. Before the study, they were treated with anti-helmintic drugs and vaccinated against several infectious diseases. Animals were inoculated intraperitoneally with $4.0 \times 10^{3}$ blood trypomastigotes $/ \mathrm{kg}$ of body weight of the T. cruzi Be-78, Y and ABC strains.

This project was approved by the ethics committee for animal experimentation of UFOP. All procedures and experimental protocols were performed according to Colégio Brasileiro de Experimentação Animal instructions for the use of animals in experimental conditions.

Fresh blood test (FB) - Parasitemia was determined microscopically by fresh blood collected from the marginal ear vein daily from the 10th-30th day post-infection.

$B C$ - Parasite detection was performed by culturing $10 \mathrm{~mL}$ blood samples and processing them according to Chiari et al. (1989) with some modifications. Blood samples were collected 30 days after inoculation during the acute phase. During the chronic phase, $\mathrm{BC}$ was carried out at regular intervals of six months (four BC/dog). Immediately after collection, the blood was centrifuged at $1,000 \mathrm{~g}, 4^{\circ} \mathrm{C}$ for $10 \mathrm{~min}$, in order to remove the plasma.

The packed blood cells were washed by centrifugation at $4^{\circ} \mathrm{C}$ in $5 \mathrm{~mL}$ of liver infusion tryptose (LIT) medium, resuspended in $5 \mathrm{~mL}$ of LIT medium and uniformly distributed between two plastic tubes. Cultures were maintained at $28^{\circ} \mathrm{C}$, homogenized weekly, and examined monthly for 120 days.

Considering the number of positive $\mathrm{BC}$ tubes during the chronic phase, the animals were arbitrarily classified into one of three levels: "low parasitemia": dogs with 0-1 positive tube; "medium parasitemia": dogs with 2-4 positive tubes; and "high parasitemia": dogs with 5-8 positive tubes.

Necropsy of the animals - All dogs were euthanized and $0.5 \mathrm{~cm}^{3}$ fragments of the left and right atria, left and right ventricles, interventricular septum and apex were obtained from each dog, cut and frozen at $-70^{\circ} \mathrm{C}$ for posterior parasite kDNA detection by PCR (T-PCR) or preserved in $10 \%$ formalin for examination of TP by immunohistochemistry (IMH).
In blood PCR (B-PCR) - For PCR of blood, 10mL of blood was collected in parallel with BC. Blood samples were mixed with an equal volume of a $6 \mathrm{M}$ guanidine hydrochloride-0.2 M EDTA solution and stored for two weeks at rt (Ávila et al. 1990), followed by boiling for 15 min before DNA extraction from $200 \mu \mathrm{L}$ of the sample (Gomes et al. 1998).

In tissue PCR (T-PCR) - Tissue samples collected 24 months after infection were thawed, minced, subjected to alkaline lysis with $50 \mathrm{mM} \mathrm{NaOH}$, heated in boiling water for $10 \mathrm{~min}$ and neutralized with $130 \mathrm{mM}$ Tris- $\mathrm{HCl}$ ( $\mathrm{pH}$ 7.0). The DNA was extracted according to Vago et al. (1996), using positive and negative controls.

PCR conditions - PCR amplification was performed in a total volume of $20 \mu \mathrm{L}$ containing $0.1 \%$ Triton $\mathrm{X}-100$, $10 \mathrm{mM}$ Tris- $\mathrm{HCl}(\mathrm{pH} \mathrm{9.0),} 75 \mathrm{mM} \mathrm{KCl}, 5 \mathrm{mM} \mathrm{MgCl}$, $0.2 \mathrm{mM}$ (each) dATP, dTTP, dGTP and dCTP (Sigma), $1 \mu \mathrm{L}$ of Taq DNA polymerase (Invitrogen), 20 pmol of S35 (5' AAATAATGTACGGG(T/G)GAGATGCATGA3') and S36 (5' GGGTTCGATTGGGGTTGGTGT3') primers and $2 \mu \mathrm{L}$ of DNA for each sample (Ávila et al. 1990). The reaction mixture was overlaid with $30 \mu \mathrm{L}$ of mineral oil (Sigma) and subjected to 35 cycles of amplification in an automatic thermocycler (MJ Research programmable thermal controller PTC-100). The temperature profile was as follows: denaturation at $95^{\circ} \mathrm{C}$ for $1 \mathrm{~min}$ (with a longer initial time of $5 \mathrm{~min}$ at $95^{\circ} \mathrm{C}$ ), $65^{\circ} \mathrm{C}$ for $1 \mathrm{~min}$ for primer annealing and $72^{\circ} \mathrm{C}$ for $1 \mathrm{~min}$ for extension, with a final incubation at $72^{\circ} \mathrm{C}$ for $10 \mathrm{~min}$ to extend the annealed primers. The PCR products were visualized by $6 \%$ polyacrylamide gel electrophoresis followed by silver staining (Santos et al. 1993). All DNA extraction steps and reaction mixtures used for PCR were monitored and compared to positive and negative controls. The PCR was considered as negative after three DNA extractions of each sample and two amplifications of each extraction.

$I M H$ - Tissue fragments were processed for embedding in paraffin and $5 \mu \mathrm{m}$-thick sections were examined. IMH staining was then performed according to the methodology of Barbosa (1985). Canine heart sections obtained during the acute phase of $T$. cruzi infection were used as positive control, and the absorbed antiserum samples or normal rabbit's serum samples were used instead of rabbit anti-T. cruzi sera as negative controls. Examination was carried out using an optical microscope at 40X magnification and 30 fields were assessed per sample. The presence of $T$. cruzi antigens and amastigotes was assessed.

Statistical analyses - To compare the positivity among the different methods, the chi-square test was applied. The results obtained by BC, B-PCR and T-PCR were evaluated by the McNemar chi-square test. Results were considered significant at $\mathrm{p}<0.05$.

\section{RESULTS}

\section{Blood Parasitism}

Acute phase (FB, $B C$ and $B-P C R)$ - All infected dogs exhibited a positive result for parasitemia upon examination of FB. However, the parasite was detected at dif- 
ferent times depending on the T. cruzi strain inoculated (from the 19th-30th, 13th-21st and 13th-30th days postinoculation in animals infected with $\mathrm{Be}-78, \mathrm{Y}$ and $\mathrm{ABC}$ T. cruzi strains, respectively). In addition, the number of tests necessary for parasite detection was variable among animals inoculated with different strains. The cumulative positivity of FB was similar among animals inoculated with Be-78 (18.7\%) and Y (26.2\%) and significantly higher in those inoculated with ABC (73.7\%) (Table I). Thus, it was necessary to perform $5.3,3.8$ or 1.4 tests to detect the parasites in animals inoculated with strain Be$78, \mathrm{Y}$ or $\mathrm{ABC}$ strain, respectively.

Similar results were observed for BC and PCR assays performed during the acute phase. In general, the parasite was detected in the blood of infected animals by both tests, with the exception of a blood sample obtained from one dog inoculated with $\mathrm{ABC}$ strain that revealed negative results even after six repetitions.

Chronic phase (BC and B-PCR) - During the chronic phase, $100 \%$ of the animals inoculated with $\mathrm{Be}-78$ and $\mathrm{ABC}$ strains presented at least one positive $\mathrm{BC}$, whereas only $25 \%$ of the animals inoculated with $\mathrm{Y}$ strain revealed a positive $\mathrm{BC}$. In addition, the positive test frequency for two years of evaluation was also similar among animals inoculated with strains Be-78 (75\%) and $\mathrm{ABC}$ strains $(62.5 \%)$; however, a significantly lower $(\mathrm{p}<0.05)$ number of positive $\mathrm{BC}$ were observed in animals inoculated with Y strain (6.2\%) (Table I).

Considering all positive $\mathrm{BC}$ tests performed during the chronic phase of infection, $61 \%(14 / 23)$ and $39 \%(9 / 23)$ were obtained in the first and second years, respectively, after inoculation. These results reveal a decrease in test positivity after the first year of evaluation. Interestingly, this decrease was only observed in animals inoculated with the $\mathrm{ABC}$ strain. In these dogs, $87.5 \%(7 / 8)$ of the positive $\mathrm{BC}$ were carried out during the first year of infection and $37.5 \%(p<0.05)(3 / 8)$ were detected during the second year of infection. In contrast, the frequencies of positive $\mathrm{BC}$ tests performed using samples obtained from dogs inoculated with the Be-78 (75\% and $75 \%)$ and $\mathrm{Y}(12.5 \%$ and $0 \%)$ strains were similar during the first and second year of examination, respectively.
Parasitemia of animals was also evaluated by analysis of the frequency of positive tubes (eight tubes/dog) in relation to the number of positive $\mathrm{BC}$ per animal. Fig. 1 shows the frequency of positive tubes and $\mathrm{BC}$ in animals infected with the different $T$. cruzi strains. No significant differences were observed between the frequencies of positive tubes and the number of $\mathrm{BC}$ among the animals inoculated with Be-78 and $\mathrm{ABC}$ strains, but these values were significantly higher $(p<0.05)$ than those observed for animals inoculated with Y strain.

Considering the number of positive tubes in $\mathrm{BC}$, $33 \%$ of the animals were classified as presenting "low parasitemia", 50\% "median parasitemia" and 17\% "high parasitemia".

T. cruzi $\mathrm{kDNA}$ was detected in $40(83.3 \%)$ out of the 48 blood samples obtained from dogs inoculated with different $T$. cruzi strains. In addition, B-PCR was positive for at least one sample obtained from each evaluated animal. No significant difference was found in blood samples obtained from dogs inoculated with Be-

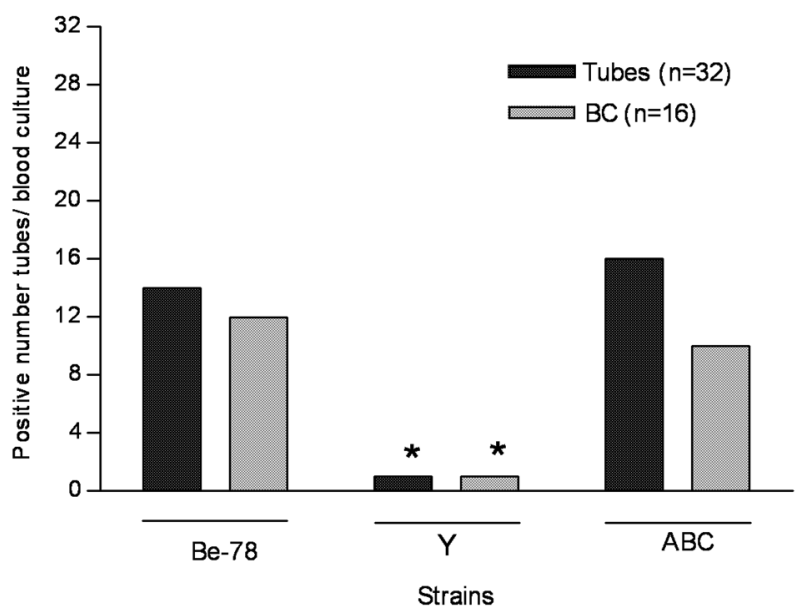

Fig. 1: frequency of positive tubes in blood culture $(\mathrm{BC})$ and of positive BC performed during the chronic phase of Trypanosoma cruzi infection of Beagle dogs inoculated with $4.0 \times 10^{3}$ blood trypomastigotes of the Be-78, Y or ABC strains; ${ }^{*} \mathrm{p}<0.05$.

\section{TABLE I}

Fresh blood (FB) examination, blood culture (BC) and blood-PCR (B-PCR) results performed during the acute phase and chronic phase of the infection in Beagle dogs inoculated with $4.0 \times 10^{3}$ blood trypomastigotes of the Be-78, Y or ABC Trypanosoma cruzi strains

\begin{tabular}{|c|c|c|c|c|c|c|}
\hline \multirow[b]{4}{*}{ Method/Total of tests } & \multicolumn{6}{|c|}{ Time of infection } \\
\hline & \multicolumn{3}{|c|}{ Acute phase } & \multicolumn{3}{|c|}{ Chronic phase } \\
\hline & \multicolumn{6}{|c|}{ T. cruzi strains } \\
\hline & $\mathrm{Be}-78$ & $\mathrm{Y}$ & $\mathrm{ABC}$ & $\mathrm{Be}-78$ & $\mathrm{Y}$ & $\mathrm{ABC}$ \\
\hline$+\mathrm{FB}^{b} /$ Total of FB (\%) & $15 / 80(18.7)$ & $21 / 80(26.2)$ & $59 / 80(73.7)^{a}$ & NP & NP & NP \\
\hline +BC/Total of BC (\%) & $4 / 4(100)$ & $4 / 4(100)$ & $4 / 4(100)$ & $12 / 16(75)$ & $1 / 16(6.2)^{a}$ & $10 / 16(62.5)$ \\
\hline$+\mathrm{B}-\mathrm{PCR}^{c} /$ Total of B-PCR (\%) & $4 / 4(100)$ & $4 / 4(100)$ & $3 / 4(75)$ & $16 / 16(100)$ & $9 / 16(56.3)^{a}$ & $15 / 16(93.7)$ \\
\hline
\end{tabular}

a: $\mathrm{p}<0.05$ : significant difference; NP: not performed; $+\mathrm{BC}$ : positive blood culture; +B-PCR: positive B-PCR ( $c$ : performed in four samples of blood from each dog at regular intervals of six months during the chronic phase); +FB: positive fresh blood test ( $b$ : performed for 20 consecutive days on each dog in the acute phase of infection). 
$78(100 \%)$ and $\mathrm{ABC}$ strains (93.7\%). These indexes were significantly higher than those observed for animals inoculated with strain Y (56.3\%) (Table I). Considering all positive $\mathrm{B}-\mathrm{PCR}$ reactions performed during the $\mathrm{CP}$ of infection, $52.5 \%$ (21/40) were obtained during the first and $47.5 \%$ (19/40) during the second year after inoculation of dogs, with similar positivity observed for both groups during the two years of observation. Representative B-PCR samples obtained from groups of dogs infected with different $T$. cruzi strains are shown in Fig. 2.

\section{Tissue Parasitism}

Acute phase (IMH) - In all animals necropsied during the acute phase of infection, amastigotes were detected in at least one of the six heart fragments examined. In a total of 24 fragments, the rate of positivity (amastigotes isolated/nests) according to the strain was $95.8 \%(23 / 24)$ for animals inoculated with Be-78 strain, 70.8\% (17/24) for animals inoculated with ABC strain and only $29.2 \%$ (7/24) for dogs inoculated with Y strain.

The number of amastigotes varied among animals inoculated with different $T$. cruzi strains. Thus, 101 isolated amastigotes and 183 nests were observed in 720 microscopic fields of fragments obtained from the hearts of animals inoculated with Be-78 strain. Among animals inoculated with $\mathrm{Y}$ strain, an intense inflammatory processes and few amastigote nests (4/720 fields) were observed. However, a greater number of isolated amastigotes (52/720 fields) or small groups of amastigotes were observed to be associated with inflammatory process. Moreover, parasitism of the cardiac tissue in animals inoculated with $\mathrm{ABC}$ strain showed intermediary intensity between animals inoculated with the Be-78 or Y strains, with 20 isolated amastigotes and 53 nests/720 fields observed. In these animals, TP was associated with the inflammatory process (Fig. 3).

Chronic phase (IMH and T-PCR) - No parasites were found in any heart fragments obtained from animals during the chronic phase (24 months after inoculation) by IMH. However, DNA fragments of T. cruzi were detected in $84.5 \%$ of the tissue samples obtained from the left and right atria, left and right ventricles, interventricular septum and apex of dogs infected with Be-78, Y or $\mathrm{ABC}$ strains by T-PCR. Considering the different heart areas, T-PCR was positive for at least three samples from each animal evaluated. A total of $75 \%, 87.5 \%$ and $91.3 \%$ of the tissue samples were positive for animals infected

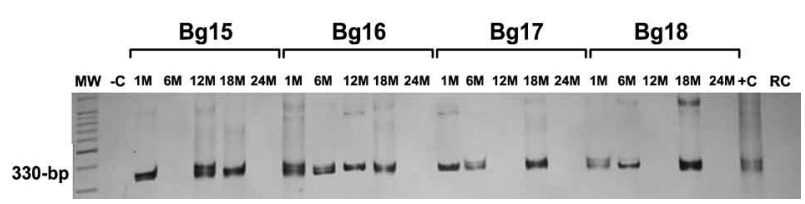

Fig. 2: representative gel showing the specific amplification of $330 \mathrm{bp}$ fragments of kDNA minicircles of Trypanosoma cruzi in the blood of infected Beagle dogs (Bg 15, Bg 16, Bg 17 and Bg 18) with $4.0 \times 10^{3}$ blood trypomastigotes of the $\mathrm{Y}$ strain during 24 months of evaluation. MW-DNA (100 pb ladder); Bg: Beagle dog; M: month; RC: reagents control; $+\mathrm{C}$ : infected/positive control dog; $-\mathrm{C}$ : negative control dog. strain $\mathrm{Be}-78, \mathrm{Y}$ or ABC. There was no significant difference among animals infected with the different strains (Table II).

$B C$ and $B-P C R$ - During the acute phase of infection, $91.6 \%$ of the samples analyzed were positive for both $\mathrm{BC}$ and $\mathrm{B}-\mathrm{PCR}$, and $8.4 \%$ only for $\mathrm{BC}$. These results indicate that $\mathrm{BC}$ and B-PCR showed similar sensitivity during this phase of the disease (Table III). During the chronic phase, $47.9 \%$ of the samples analyzed were positive for $\mathrm{BC}$ and $\mathrm{B}-\mathrm{PCR}, 35.4 \%$ for $\mathrm{B}-\mathrm{PCR}$ alone and $16.7 \%$ were negative for both tests (Table III). Positive B-PCR was significantly more frequent than positive $\mathrm{BC}$. The sensitivities of $\mathrm{BC}$ in relation to B-PCR during the first and second years of infection for dogs inoculated with different strains were $66.7 \%$ and $47.4 \%$, respectively (Table III).

$B C, B-P C R$ and T-PCR - The correlation between blood and TP was evaluated for BC, B-PCR and T-PCR performed in paired form 24 months after inoculation of

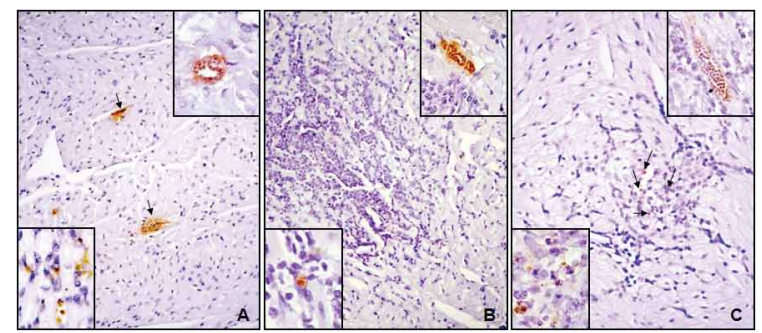

Fig 3: photomicrography of Beagle dogs myocardium infected with 4.0 x $10^{3}$ blood trypomastigotes of Be-78, Y or ABC Trypanosoma cruzi strains and euthanized at the acute phase. A: Be-78 strain: nests or isolated amastigotes (arrows) with absence of inflammatory process; B: Y strain: intense inflammatory process and absence of parasitism; $\mathrm{C}$ : ABC strain: moderate inflammatory process and isolated amastigotes; inserts: nests (upper) or isolated amastigotes (lower) observed in all strains. Imunohistochemistry Peroxidase Anti-Peroxidase. A, B and C: $160 \mathrm{X}$; inserts: $1000 \mathrm{X}$.

\section{TABLE II}

PCRs in different heart areas performed after necropsy of 12 Beagle dogs two years after inoculation with

$4.0 \times 10^{3}$ blood trypomastigotes of the Be-78, Y or ABC strains of Trypanosoma cruzi

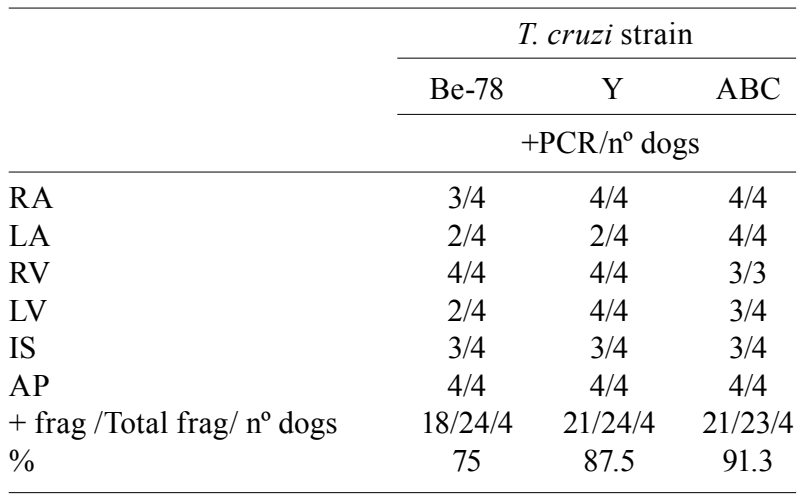

AP: apex; frag.: fragment; IS: interventricular septum; LA: left atrium; LV: left ventricle; RA: right atrium; RV: right ventricle. 
TABLE III

Comparison between blood culture (BC) and blood-PCR (B-PCR) results obtained during the acute phase and chronic phase (two years) of the Trypanosoma cruzi infection of the 12 Beagle dogs inoculated with $4.0 \times 10^{3}$ blood trypomastigotes of the $\mathrm{Be}-78, \mathrm{Y}$ or ABC strains

\begin{tabular}{lcccc}
\hline & & \multicolumn{2}{c}{ Positive tests (\%) } \\
\cline { 2 - 5 } & & \multicolumn{2}{c}{ Chronic phase } \\
\cline { 2 - 5 } & Acute phase & 1st year & $\mathrm{n}=24$ & $\mathrm{n}=48$ \\
\hline & $\mathrm{n}=12$ & $14(58.3 \%)$ & $9(37.5 \%)$ & $23(47.9 \%)$ \\
+ +BC/+B-PCR & $11(91.6 \%)$ & 0 & 0 & 0 \\
+BC/-B-PCR & $1(8.4 \%)$ & $7(29.2 \%)$ & $10(41.7 \%)$ & $17(35.4 \%)$ \\
-BC/+B-PCR & 0 & $3(12.5 \%)$ & $5(20.8 \%)$ & $8(16.7 \%)$ \\
-BC/-B-PCR & 0 & $\mathrm{p}<0.05^{a}$ & $\mathrm{p}<0.05^{a}$ & $\mathrm{p}<0.05^{a}$ \\
$\chi^{2}$ McNemar & $\mathrm{NS}$ & $66.7 \%$ & $47.4 \%$ & $57.5 \%$ \\
Sensitivity BC & $100 \%$ & $100 \%$ & $100 \%$ & $100 \%$ \\
Specificity BC & - & & & total \\
\hline
\end{tabular}

$a: \mathrm{p}<0.05$, significant difference, when comparing positivity BC to B-PCR.

12 Beagle dogs with Be-78, Y or ABC T. cruzi strains (Fig. 4). The positivity was 33\% (4/12) for BC, 66.7\% (8/12) for B-PCR and 100\% (12/12) for T-PCR. Considering all dogs evaluated, a higher sensitivity was observed for T-PCR compared to that observed for the other tests performed. The sensitivity of $\mathrm{BC}$ in relation to B-PCR, $\mathrm{BC}$ in relation to T-PCR and B-PCR in relation to T-PCR were $50 \%, 33.3 \%$ and $66.7 \%$, respectively (Table IV). On the other hand, the parasite was only detected in heart tissue by T-PCR in animals infected with Y strain. blood parasitism was not detected in any animal evaluated by BC or B-PCR (Fig. 4).

All tests performed using blood or tissue samples obtained from animals infected with Be-78 strain exhibited a similar frequency of positivity. A high correlation was observed between parasite levels in the peripheral blood and in heart tissue. In animals inoculated with ABC strain, the positivity of B-PCR and T-PCR was also similar, with the parasite detected with significantly lower frequency by BC. In animals infected with Y strain, the parasite was only detected in heart tissue by T-PCR. Blood parasitism was not detected in any animal evaluated by BC or B-PCR (Fig. 4).

\section{DISCUSSION}

Evaluation of the parasitism level of peripheral blood in chronic Chagas disease has been evaluated by several studies. In general, the sensitivity of the parasitological tests, xenodiagnosis and $\mathrm{BC}$ assays is related to the blood parasitism level, which could be related to genetic characteristics of the T. cruzi strains. These genetic characteristics vary according to geographic regions (Coura et al. 1984). However, due to ethical reasons, most of these studies were performed in humans during the acute or chronic phases of the infection and did not evaluate the relationship between the intensity of heart tissue and blood parasitism.

During the acute phase of the infection, the presence of the parasite was easily demonstrated in all animals by the three techniques used herein (FB, BC and B-PCR).

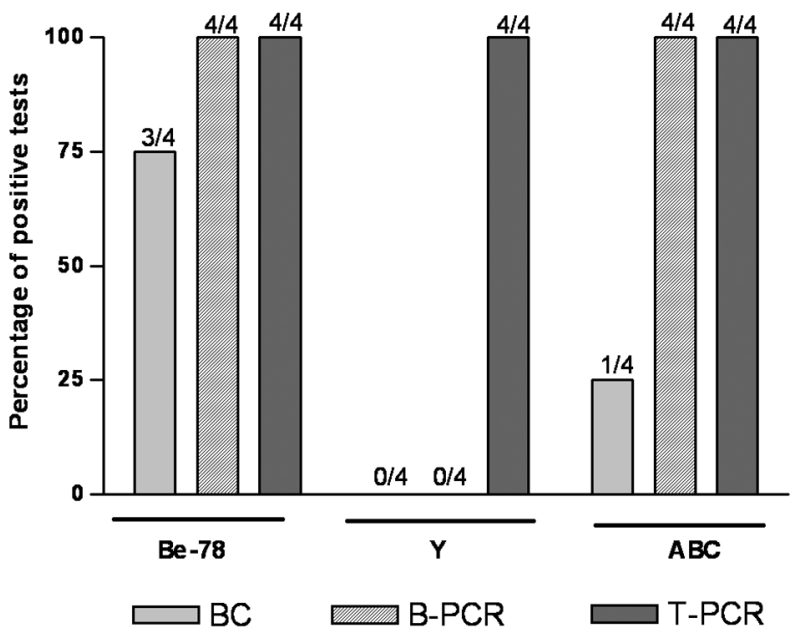

Fig. 4: comparison among the results obtained by blood culture (BC), blood-PCR (B-PCR) and tissue-PCR (T-PCR) performed after 24 months of the Trypanosoma cruzi infection of the 12 Beagle dogs inoculated with $4.0 \times 10^{3}$ blood trypomastigotes of the Be-78, $\mathrm{Y}$ or $\mathrm{ABC}$ strains.

However, the variation in parasitemia levels among animals infected with different $T$. cruzi strains was demonstrated by the frequency of positive FB tests. Considering the frequency of positive tests, we verified the necessity of performing a greater number of tests to detect parasites in animals inoculated with the Be-78 strain compared to those inoculated with the $\mathrm{Y}$ and $\mathrm{ABC}$ strains. No correlation was observed between blood parasitism levels during the acute and chronic phases of infection because, during the chronic phase, animals inoculated with the Y strain showed significantly lower blood parasitism levels than those inoculated with Be-78 and $\mathrm{ABC}$, as evidenced by BC and B-PCR.

In the present work, a reduction in parasitemia levels throughout the chronic phase of the infection was demonstrated by the decrease in positive $\mathrm{BC}$ observed during the second year compared to the first year of evaluation. 
TABLE IV

Comparison between blood culture (BC), blood-PCR (B-PCR) and tissue-PCR (T-PCR) results obtained after 24 months of Trypanosoma cruzi infection of the 12 Beagle dogs inoculated with $4.0 \times 10^{3}$ blood trypomastigotes of the $\mathrm{Be}-78, \mathrm{Y}$ or $\mathrm{ABC}$ strains

\begin{tabular}{|c|c|c|c|}
\hline \multirow[b]{2}{*}{$+\mathrm{BC} /+\mathrm{B}-\mathrm{PCR} /+\mathrm{T}-\mathrm{PCR}$} & \multicolumn{3}{|c|}{$\begin{array}{c}\text { Chronic phase ( } 24 \text { months after inoculation) } \\
\text { n positive/n examined }(\%)\end{array}$} \\
\hline & \multicolumn{3}{|c|}{$4 / 12(33.3 \%)$} \\
\hline +BC/-B-PCR/+T-PCR & \multicolumn{3}{|c|}{$4 / 12(33.3 \%)$} \\
\hline -BC/+B-PCR/+T-PCR & \multicolumn{3}{|c|}{$8 / 12(66.7 \%)$} \\
\hline$-\mathrm{BC} / \mathrm{B}-\mathrm{PCR} /+\mathrm{T}-\mathrm{PCR}$ & \multicolumn{3}{|c|}{$4 / 12(33.3 \%)$} \\
\hline -BC/-B-PCR/-T-PCR & \multicolumn{3}{|c|}{0} \\
\hline & BC $\times$ B-PCR & BC $\times$ T-PCR & B-PCR x T-PCR \\
\hline$\chi^{2} \mathrm{McNemar}$ & NS & $\mathrm{p}<0.05^{a}$ & NS \\
\hline Sensitivity & $50 \%$ & $33.3 \%$ & $66.7 \%$ \\
\hline
\end{tabular}

$a$ : $\mathrm{p}<0.05$ : significant difference when comparing positivity BC to T-PCR; NS: not significative.

Interestingly, this decrease was detected in only animals infected with the ABC strain. On the other hand, the reduction in parasite load throughout T. cruzi infection was not verified by B-PCR. In addition, PCR was more sensitive than $\mathrm{BC}$ for the detection of parasitemia or parasite kDNA in distinct blood samples collected from dogs infected with each parasite strain. The present results suggest that BC and B-PCR sensitivities are related to the parasite strain. An important difference was observed for BC, as well as PCR positivity performed using blood samples from animals infected with the three different $T$. cruzi strains studied. BC and/or PCR detected the parasite or parasite kDNA in approximately $97 \%$ of the tests carried out for animals infected with Be-78 and $\mathrm{ABC}$ strains. On the other hand, only $56.3 \%$ of the animals infected with Y strain were positive. The difference in positivity for $\mathrm{BC}$ could be explained by morphological differences in the strains considered, as previously has demonstrated that $T$. cruzi strains with a predominance of slender blood trypomastigotes are more sensitive to host immune mechanisms than strains with a predominance of large or stout trypomastigotes (Brener 1969). This hypothesis was suggested by other authors who verified different courses of parasitemia in dogs inoculated with Be-62 or Be-78 strains, with a predominance of slender and large trypomastigotes (Lana et al. 1992, Araújo et al. 2002) associated with lower and higher $\mathrm{BC}$, xenodiagnosis and PCR, respectively. According to Coura et al. (1984), the sensitivity of parasitological tests seems to reflect the different genetic constitution of circulating $T$. cruzi strains, which vary according to geographical regions and naturally with the polymorphism of the blood trypomastigote.

Arbitrary classification of the animals according to the parasitemic level based on $\mathrm{BC}$ was also associated with the $T$. cruzi strain assessed. Thus, animals with "high parasitemia", presented a higher frequency of positive B-PCR and IMH, while the opposite was observed in animals classified as "low parasitemia". In this scenario, the low positivity of BC and PCR performed using peripheral blood samples obtained from animals infected with strain Y reflect the low parasitemia of these animals. Additionally, negative BC and PCR results for patients and animals with positive serology have been reported. This fact has been explained by the occurrence of patients with low parasitemia, for whom parasites could rarely or never be detected (Castro et al. 2002).

A high frequency of $T$. cruzi kDNA in representative portions of the heart was observed for all animals evaluated 24 months after infection. These results showed, as previously reported in human chronic Chagas disease (Lages-Silva et al. 2001, Elias et al. 2003), that fragments of $T$. cruzi kDNA remain in the heart tissue after longterm infection of dogs. On the other hand, Machado et al. (2001) did not detect T. cruzi DNA in the heart tissue of dogs inoculated with different $T$. cruzi strains using primers that amplify a $195 \mathrm{bp}$ repetitive sequence of the genomic DNA, in contrast to the PCR condition used herein. However, the differences in the primers and PCR methodologies used require consideration.

With regard to the IMH results, the parasitism and inflammatory process pattern was again different, suggesting a large influence of the parasite strain on the results obtained for injuries incurred during the acute phase of infection. During the chronic phase, the IMH reaction was negative for all heart fragments. The low sensitivity of the IMH at this stage of infection has already been demonstrated for dog tissues by other authors (Caliari et al. 1994, Machado et al. 2001, Cruz et al. 2006). Lages-Silva et al. (2001) also verified that PCR exhibits greater sensitivity than IMH for detecting the presence of T. cruzi in the esophagus of chagasic patients during the chronic phase of the infection.

Taken together, these results corroborate the importance of $T$. cruzi strains in the sensitivity of parasitological techniques (FB, BC, B-PCR and IMH) used for diagnosis of infection. Furthermore, our data provide definitive evidence of long-term persistence of T. cruzi in the heart tissue of dogs infected with different $T$. cruzi strains.

\section{ACKNOWLEDGMENTS}

To Lívia de Figueiredo Diniz and Geovam Crepalde, for the care of Beagle dogs, and the Rede Mineira de Bioterismo da FAPEMIG. 


\section{REFERENCES}

Araújo FM, Bahia MT, Magalhães NM, Martins-Filho OA, Veloso VM, Carneiro CM, Tafuri WL, Lana M 2002. Follow-up of experimental chronic Chagas' disease in dogs: use of polymerase chain reaction (PCR) compared with parasitological and serological methods. Acta Trop 81: 21-31.

Ávila HA, Gonçalves AM, Nehme NC, Morel CM, Simpson L 1990. Schizodeme analysis of Trypanosoma cruzi stocks from South and Central America by analysis of PCR-amplifiable minicircle variable region sequences. Mol Biochem Parasitol 42: 175-188.

Ávila HA, Pereira JB, Thiemann O, De Paiva E, DeGrave W, Morel CM, Simpson L 1993. Detection of Trypanosoma cruzi in blood specimens of chronic patients by polymerase chain reaction amplification of kinetoplast minicircle DNA: comparison with serology and xenodiagnosis. J Clin Microbiol 31: 2421-2426.

Bahia MT, Tafuri WL, Caliari MV, Veloso VM, Carneiro CM, Coelho GL, Lana M 2002. Comparison of Trypanosoma cruzi infection in dogs inoculated with blood or metacyclic trypomastigotes of Berenice-62 and Berenice-78 strains via intraperitoneal and conjunctival routes. Rev Soc Bras Med Trop 35: 339-345.

Barbosa AJA 1985. Método imunocitoquímico para a identificação de amastigotas do Trypanosoma cruzi em cortes histológicos de rotina. Rev Inst Med Trop Sao Paulo 27: 293-297.

Brener Z 1965. Comparative studies of different strains of Trypanosoma cruzi. Ann Trop Med Parasitol 59: 19-26.

Brener Z 1969. The behavior of slender and stout forms of Trypanosoma cruzi in the blood-stream of normal and immune mice. Ann Trop Med Parasitol 63: 215-220.

Caliari MV, Lana M, Oliveira ER, Barbosa AJ, Tafuri WL 1994. Immunocytochemical study of tissue parasitism of dog adrenal glands in experimental Chagas' disease. Parasite 1: 397-400.

Castro AM, Luquetti AO, Rassi A, Rassi GG, Chiari E, Galvão LM 2002. Blood culture and Polymerase Chain Reaction for the diagnosis of the chronic phase of human infection with Trypanosoma cruzi. Parasitol Res 88: 894-900.

Chiaramonte MG, Frank FM, Furer GM, Taranto NJ, Margni RA, Malchiodi EL 1999. Polymerase chain reaction reveals Trypanosoma cruzi infection suspected by serology in cutaneous and mucocutaneous leishmaniasis patients. Acta Trop 72: 295-308.

Chiari E 1999. Chagas disease diagnosis using polymerase chain reaction, hemoculture and serologic methods. Mem Inst Oswaldo Cruz 94 (Suppl. I): 299-300.

Chiari E, Dias JCP, Lana M, Chiari CA 1989. Hemocultures for the parasitological diagnosis of human chronic Chagas' disease. Rev Soc Bras Med Trop 22: 19-23.

Coura JR, Abreu LL, Dubois LEG, Correia-Lima F, Arruda JRE, Wellcox HPF, Anunzioto N, Pestana W 1984. Morbidade da doença de Chagas. II - Estudos seccionais em quatro áreas de campo no Brasil. Mem Inst Oswaldo Cruz 79: 101-124.

Cruz RE, Macedo AM, Barnabe C, Freitas JM, Chiari E, Veloso VM, Carneiro CM, Bahia MT, Tafuri WL, Lana M 2006. Further genetic characterization of the two Trypanosoma cruzi Berenice strains (Be-62 and Be-78) isolated from the first human case of Chagas disease (Chagas, 1909). Acta Trop 97: 239-246.

Elias FE, Vigliano CA, Laguens RP, Levin MJ, Berek C 2003. Analysis of the presence of Trypanosoma cruzi in the heart tissue of three patients with chronic Chagas' heart disease. Am J Trop Med Hyg 68: 242-247.

Gomes ML, Galvão LM, Macedo AM, Pena SD, Chiari E 1999. Cha- gas' disease diagnosis: comparative analysis of parasitologic, molecular, and serologic methods. Am J Trop Med Hyg 60: 205-210.

Gomes ML, Macedo AM, Vago AR, Pena SDJ, Galvão LMC, Chiari E 1998. Trypanosoma cruzi: Optimization of Polymerase Chain Reaction for detection in human blood. Exp Parasitol 88: 28-33.

Guedes PM, Urbina JA, de Lana M, Afonso LC, Veloso VM, Tafuri WL, Machado-Coelho GL, Chiari E, Bahia MT 2004. Activity of the new triazole derivative albaconazole against Trypanosoma (Schizotrypanum) cruzi in dog hosts. Antimicrob Agents Chemother 48: 4286-4292.

Lages-Silva E, Crema E, Ramirez LE, Macedo AM, Pena SD, Chiari E 2001. Relationship between Trypanosoma cruzi and human chagasic megaesophagus: blood and tissue parasitism. Am J Trop Med Hyg 65: 435-441.

Lana M, Chiari CA 1986. Caracterização biológica comparativa das cepas Berenice-78 de Trypanosoma cruzi, isoladas da mesma paciente em diferentes períodos. Mem Inst Oswaldo Cruz 81: 247-253.

Lana M, Chiari E, Tafuri WL 1992. Experimental Chagas' disease in dogs. Mem Inst Oswaldo Cruz 87: 59-71.

Lana M, Tafuri WL, Caliari MV, Bambirra EA, Chiari CA, Leite VHR, Barbosa AJA, Toledo MJO, Chiari E 1988. Fase crônica cardíaca fibrosante da tripanosomíase cruzi experimental no cão. Rev Inst Med Trop Sao Paulo 21: 113-121.

Machado EM, Fernandes AJ, Murta SM, Vitor RW, Camilo DJJ, Pinheiro SW, Lopes ER, Adad SJ, Romanha AJ, Dias JCP 2001. A study of experimental reinfection by Trypanosoma cruzi in dogs. Am J Trop Med Hyg 65: 958-965.

Marcon GE, Andrade PD, de Albuquerque DM, Wanderley JS, de Almeida EA, Guariento ME, Costa SC 2002. Use of a nested Polymerase Chain Reaction (N-PCR) to detect Trypanosoma cruzi in blood samples from chronic. Diagn Microbiol Infect Dis 43: 39-43.

Portela-Lindoso AA, Shikanai-Yasuda MA 2003. Chronic Chagas' disease: from xenodiagnosis and hemoculture to polymerase chain reaction. Rev Saude Publica 37: 107-115.

Russomando G, Figueredo A, Almiron M, Sakamoto M, Morita K 1992. Polymerase chain reaction-based detection of Trypanosoma cruzi DNA in serum. J Clin Microbiol 302: 864-868.

Santos FR, Pena SDJ, Epplen JT 1993. Genetic and population study of a Y-linked tetranucleotide repeat DNA polymorphism with a simple non-isotopic technique. Hum Genet 90: 655-656.

Silva LHP, Nussenzweig V 1953. Sobre uma cepa de Trypanosoma cruzi altamente virulenta para o camundongo branco. Folia Clin Biol 20: 191-203.

Vago AR, Macedo AM, Adad SJ, Reis DA, Corrêa-Oliveira R 1996. PCR detection of Trypanosoma cruzi DNA in esophageal tissues of patients with chronic digestive Chagas' disease. Lancet 348: 891-892.

WHO - World Health Organization 2005. Tropical Disease Research: progress 2003-2004. Special Programme for Research \& Training in Tropical Diseases. Programme Report 17, Geneva, 31-33.

Wincker P, Bosseno MF, Britto C, Yaksic N, Cardoso MA, Morel CM, Breniere SF 1994a. High correlation between Chagas' disease serology and PCR-based detection of Trypanosoma cruzi kinetoplast DNA in Bolivian children living in an endemic area. FEMS Microbiol Lett 124: 419-423.

Wincker P, Britto C, Pereira JB, Cardoso MA, Oelemann W, Morel CM 1994b. Use of a simplified polymerase chain reaction procedure to detect Trypanosoma cruzi in blood samples from chronic chagasic patients in a rural endemic area. Am J Trop Med Hyg 51: 771-777. 